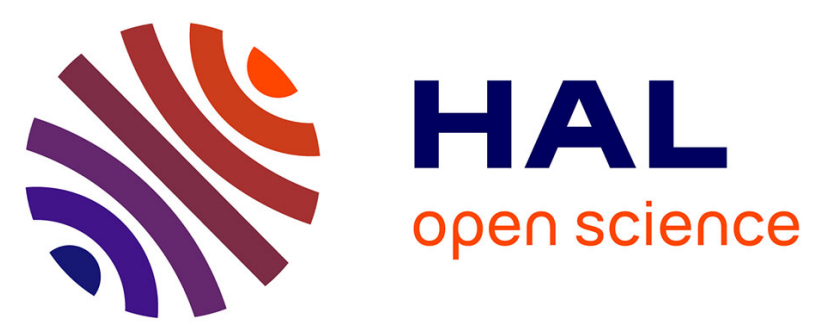

\title{
Comparison of meiofaunal diversity by combined morphological and molecular approaches in a shallow Mediterranean sediment
}

Jadwiga Rzeznik-Orignac, Dimitri Kalenitchenko, Jérôme J. Mariette, Jean-Yves Bodiou, Nadine Le Bris, Evelyne Derelle

\section{To cite this version:}

Jadwiga Rzeznik-Orignac, Dimitri Kalenitchenko, Jérôme J. Mariette, Jean-Yves Bodiou, Nadine Le Bris, et al.. Comparison of meiofaunal diversity by combined morphological and molecular approaches in a shallow Mediterranean sediment. Marine Biology, 2017, 164 (3), pp.40. 10.1007/s00227-017-30744. hal-01492903

\section{HAL Id: hal-01492903 https: / hal.sorbonne-universite.fr/hal-01492903}

Submitted on 27 Mar 2017

HAL is a multi-disciplinary open access archive for the deposit and dissemination of scientific research documents, whether they are published or not. The documents may come from teaching and research institutions in France or abroad, or from public or private research centers.
L'archive ouverte pluridisciplinaire HAL, est destinée au dépôt et à la diffusion de documents scientifiques de niveau recherche, publiés ou non, émanant des établissements d'enseignement et de recherche français ou étrangers, des laboratoires publics ou privés. 


\title{
Comparison of meiofaunal diversity by combined morphological and molecular approaches in a shallow Mediterranean sediment
}

\author{
Jadwiga Rzeznik-Orignac ${ }^{1} \cdot$ Dimitri Kalenitchenko $^{1} \cdot$ Jérôme Mariette $^{2} \cdot$ \\ Jean-Yves Bodiou ${ }^{3} \cdot$ Nadine Le Bris $^{1} \cdot$ Evelyne Derelle $^{4}$
}

Received: 12 August 2016 / Accepted: 9 January 2017

(C) Springer-Verlag Berlin Heidelberg 2017

\begin{abstract}
Fast, accurate and thorough assessments of meiofaunal communities are crucial requirements for ecological studies and routine monitoring of ecosystem status. This study scrutinizes the reliability of the molecular approach through a comparison of morphological and molecular inventories of meiofaunal diversity, with a special focus on nematodes. Sediment samples were collected from a reference coastal Mediterranean site. Metabarcoding analysis was performed using a nuclear marker (small subunit $18 \mathrm{~S}$ ribosomal RNA) and compared to a morphological analysis performed on the same sample-cores. The results from morphological and molecular inventories differed but were complementary. The molecular analysis
\end{abstract}

Responsible Editor: M. Huettel.

Reviewed by D. Cowart and an undisclosed expert.

Electronic supplementary material The online version of this article (doi:10.1007/s00227-017-3074-4) contains supplementary material, which is available to authorized users.

Jadwiga Rzeznik-Orignac

orignac@obs-banyuls.fr

1 Sorbonne Universités, UPMC Univ Paris 06, CNRS, Laboratoire d'Ecogéochimie des Environnements Benthiques (LECOB UMR 8222), Observatoire Océanologique, 66650 Banyuls/mer, France

2 MIAT, Université de Toulouse, INRA, 31326 Castanet-Tolosan, France

3 Sorbonne Universités, UPMC Univ Paris 06, CNRS, Observatoire Océanologique, 66650 Banyuls/mer, France

4 Sorbonne Universités, UPMC Univ Paris 06, CNRS, Laboratoire de Biologie Intégrative des Organismes Marins (BIOM UMR 7232), Observatoire Océanologique, 66650 Banyuls/mer, France revealed a remarkable level of diversity (16 phyla) that exceeded the traditional morphological analysis (10 phyla), showing that meiofaunal diversity can greatly exceed current perceptions. The molecular method proved powerful in detecting the presence of soft-bodied predators, such as Platyhelminthes, possibly reflecting preservation bias in morphological approaches. Even if the molecular inventory identified $57.5 \%$ of the sampled diversity, surprisingly, it has not revealed the presence of some nematode genera identified through morphological assessment. While the technique is promising, some further developments are required. As the dominant genus Sabatieria was undetected by the molecular approach, despite being present in the Silva database, improving the knowledge of specific primers should be a priority. Additionally, with $77 \%$ of nematode OTUs remaining unassigned at genera level, remedy this lower efficiency requires further investigations to provide DNA-sequences of all morphologically identified species.

\section{Introduction}

Marine sediments are teeming with tiny invertebrates that range in size from $40 \mu \mathrm{m}$ to $1 \mathrm{~mm}$ and have densities up to several million individuals per $\mathrm{m}^{2}$, which are frequently referred to as meiofauna. Marine meiofauna include representatives from Nematoda, Copepoda, Turbellaria, Kinhoryncha, Gastrotricha and Ostracoda, as well as juveniles of macrofauna (Higgins and Thiel 1988). Approximately $60 \%$ of animal phyla have meiofaunal representatives (Higgins and Thiel 1988; Giere 2009) and therefore, these tiny animals constitute a major part of marine biodiversity (Snelgrove 1999). Meiofauna include primarily metazoans, but also ecologically relevant protozoans, such as ciliates 
and foraminiferans, which are often identified from meiobenthological studies (Higgins and Thiel 1988). Meiofauna play an important role in sediment biogeochemical and ecological processes (Giere 2009; Bonaglia et al. 2014). In marine sediments, these communities make essential contributions to nutrient cycling, secondary production and sediment bioturbation (Ingels et al. 2010; Nascimento et al. 2012; Bonaglia et al. 2014). Despite the high number of individuals and the ecological role of meiofaunal communities, current estimates of species richness remain largely uncertain (Lambshead and Boucher 2003). Because the morphological identification of meiofauna is very timeconsuming and requires rare taxonomic skills, benthic studies persistently suffer from the lack of information on meiofaunal community structure. The deficiency of those data becomes a limiting factor in understanding marine benthic communities and their role in ecosystem functioning, as well as in the monitoring survey of marine habitats.

The use of molecular identification techniques holds great promises to overcome these limitations (Rothberg and Leamon 2008). For prokaryote communities, knowledge of diversity has expanded by several orders of magnitude in the last decade as a result of modern DNA sequencing tools (e.g., DeLong et al. 2006; Sogin et al. 2006). The use of these environmental sequencing methods for smallsized metazoan bottom-fauna (Creer et al. 2010; Fonseca et al. 2010, 2014; Bik et al. 2012; Tang et al. 2012; Lallias et al. 2015; Dell'Anno et al. 2015) holds great promise for improvement of meiobenthic inventories. Nevertheless, the development of environmental metagenetic tools in the context of meiobenthic communities is still limited by the capacity to accurately link molecular diversity assessments to traditional morphological inventories of meiofauna. The reliable and accurate identification of organisms remains a crucial step for ecological studies and the routine monitoring of ecosystems.

The aim of this study was to compare molecular dataset consisting in total of 200,000 sequences amplified from the nuclear $18 \mathrm{~S}$ gene regions to results from a traditional morphological study performed on replicate-cores taken in one reference coastal Mediterranean site at the same time-point. The study-site was a shallow, sandy area at $27 \mathrm{~m}$ depth in the Bay of Banyuls, France. The macrofauna at this location has been monitored since 1967 (Guille 1970, 1971, Grémare et al. 2002; Labrune et al. 2007) and environmental parameters have been recorded since 1995 (SOMLIToceanographic observation network). Previous descriptions of meiofauna from the Gulf of Lion were based on morphological identification, focusing on harpacticoid copepods at the species level (Guille and Soyer 1968; Soyer 1970, 1974) or at the phyla level (Grémare et al. 2002). The present study provides the first molecular description of meiofaunal diversity at this site, combined with detailed morphological analyses. In addition to complementing current molecular databases for Mediterranean coastal meiobenthos, detailed comparisons of the two inventories not only describes their differences and similarities, but also highlights the respective performance of the two methods in addressing the overlooked meiofaunal contribution to benthic ecological functions.

\section{Materials and methods}

\section{Study site and sampling}

The general methodology was presented in Fig. 1. Sampling was carried out in the Bay of Banyuls-sur-Mer on April 2010, at the long-term coastal monitoring site "station SOLA" in the North-Western Mediterranean Sea $\left(42^{\circ} 29.294 \mathrm{~N}-03^{\circ} 08.574 \mathrm{E}\right)$. This site is a part of the oceanological observation network SOMLIT (http:// somlit.epoc.u-bordeaux1.fr), and is located less than one mile from the marine station of Banyuls. This proximity allowed sample treatment to be completed within less than $1 \mathrm{~h}$. The sediment at this location is composed of $50 \%$ fine sand, 38\% median sand and $12 \%$ silt. Three replicate sediment cores, measuring $6 \mathrm{~cm}$ in diameter and $10 \mathrm{~cm}$ in height, were collected by divers at $27 \mathrm{~m}$ depth (from a $1 \mathrm{~m}$ $\times 1 \mathrm{~m}$ square). To be able to compare datasets, the same three cores were used for both morphological and molecular analyses. In the laboratory, each core was immediately split vertically in two parts. These six samples were rinsed through $1 \mathrm{~mm}$ sieves to remove macrofauna and $40 \mu \mathrm{m}$ sieves to retrieve meiofauna. From the fraction of $40 \mu \mathrm{m}-1 \mathrm{~mm}$, organisms were isolated by centrifugation in a Ludox solution (Heip et al. 1985). The samples dedicated to the morphological analysis were fixed in a $4 \%$ formalin solution, while the samples dedicated to the molecular analysis were immediately preserved at $4{ }^{\circ} \mathrm{C}$.

\section{Processing for morphological analysis}

The samples preserved in $4 \%$ formalin were split in two or four equal parts using a sample splitter (Motoda-box). Meiofauna abundances and taxonomic composition from three subsamples (corresponding to the three cores) were obtained by counting and identifying specimens under binocular microscope. The nematode diversity, based on 100 individuals collected randomly per sample, was established by identification at genus level under optical microscope using identification keys (Platt and Warwick 1983, 1988; Platt et al. 1988). All Copepoda (Arthropoda) were identified to the genus (Lang 1975a, b; Huys et al. 1996), while Polychaeta (Annelida) were identified to the family level 
Fig. 1 Scheme of the protocol applied to analyse meiofaunal diversity from morphological and molecular methods

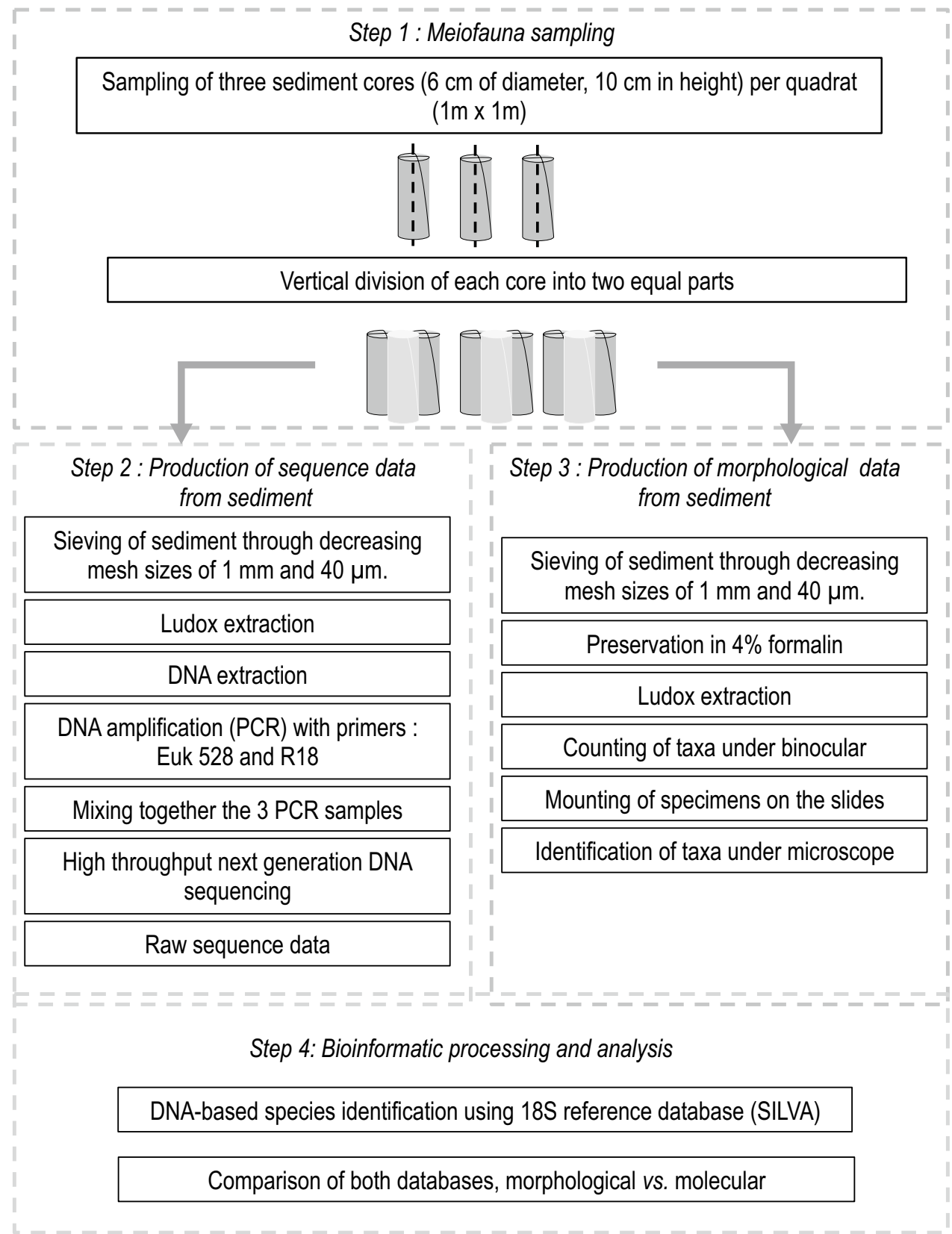

(Fauvel 1923; Westheide 1990). The remaining metazoans were identified to the class or phyla.

\section{Processing for molecular analysis}

DNA extractions were performed separately for the three replicate-cores, using the CTAB method (Winnepenninckx et al. 1993) with manual grinding. The quality of extracted DNA was checked by agarose electrophoresis $(0.8 \%$ agarose gel, TAE $0.5 x$ buffer, $20 \mathrm{~min}, 100 \mathrm{~V})$. The primers Euk528 (5'-ccgcggtaattccagctc-3') and R18 (5'-cgttatcggaattaaccagac-3') were used to amplify approximately $760 \mathrm{bp}$ of the V4-V5 regions (Hadziavidic et al. 2014) of the nuclear $18 \mathrm{~S}$ rRNA gene. The PCR cycling consisted of $2 \mathrm{~min}$ of denaturation at $95^{\circ} \mathrm{C}$, followed by $30 \mathrm{PCR}$ cycles $\left(1 \mathrm{~min}\right.$ at $95^{\circ} \mathrm{C}, 1 \mathrm{~min}$ at $55^{\circ} \mathrm{C}$ and $1 \mathrm{~min}$ at $72^{\circ} \mathrm{C}$ ) and then $4 \mathrm{~min}$ at $72^{\circ} \mathrm{C}$. The PCR products from the three samples were first gel-purified using NucleoSpin ${ }^{\circledR}$ Gel and PCR CleanUp (Macherey Nagel), quantified by Nanodrop, and then the equal quantities of DNA from each amplicon were mixed together before processed on 454 Roche FLX sequencer at the GATC Biotech Laboratory in Germany. 


\section{Bioinformatic data processing and analyses}

We applied the QIIME workflow (Caporaso et al. 2010) to the analysis of meiofaunal diversity (see SI_1 for QIIME scripts used for bioinformatics data processing analyses). The sequences generated from the pyrosequencing run were processed using the PyroNoise algorithm (Schloss et al. 2009) to remove 454 sequencing errors and the PCR single base, while the UCHIME algorithm (Edgar et al. 2011) was used to identify and remove potential chimeras (Quince et al. 2011). The average resulting sequence size was 200-220 bp and sequences shorter than $199 \mathrm{bp}$ were discarded. Aligned sequences were clustered into Operational Taxonomic Units (OTUs) using UCLUST (Edgar et al. 2011), with a similarity cut-off of $96 \%$. Taxonomic assignments were performed using Megablast against the downloaded nucleotide database Silva 119, and the OTU annotation was restricted to matches of $90 \%$ and higher. Sequence data were deposited in the GenBank/EMBL/ DDBJ short-read archive as submission ID: SRR2976849.

The software PAST (3.0) (Hammer et al. 2001) was used to perform a rarefaction analysis based on the number of nematode sampled for morphological method and the number of OTUs found by molecular method. The Primer-E software (Clarke and Warwick 2001) was used to calculate similarity index of the nematode community. Data were presence/absence transformed and Bray-Curtis similarity matrices were performed to determine if differences exist between the three samples used for morphological analysis (i.e., an indication of the local heterogeneity within the $1 \mathrm{~m}$ $\times 1 \mathrm{~m}$ square) and between the morphological and molecular datasets. The morphological inventories obtained from three samples were pooled before to compare with the diversity obtained by molecular method. Presence/absence information obtained from molecular and morphological datasets are shown in SI_2 dataset. The browser Krona (Ondov et al. 2011) was used to create the graphics.

\section{Results}

\section{Morphological assessment of meiofaunal diversity}

The mean abundance of meiofauna was $1341( \pm 356$, SD) ind. $10 \mathrm{~cm}^{-2}$. Among the 10 phyla found, Nematoda was the most abundant (77\%), followed by Arthropoda (encompassing Copepoda-15\%, Ostracoda-1\%, Amphipoda-1\%), Annelida (3\%) and other phyla, whose relative abundances were less than 1\%: Mollusca, Priapulida, Kinorhyncha, Cnidaria, Plathyhelminthes, Gastrotricha, Rotifera (Fig. 2).

The nematodes were classified into 51 genera belonging to 22 families and 4 orders (Fig. 3). The dominant

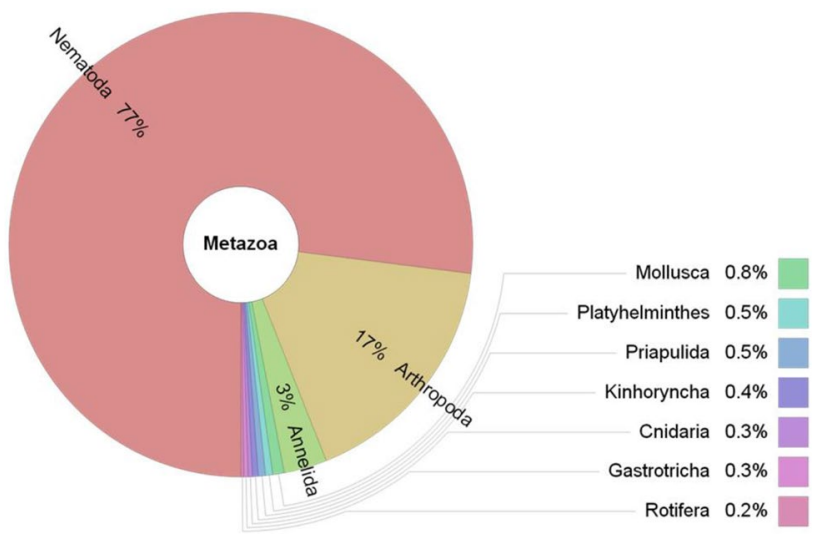

Fig. 2 Metazoan diversity assessed using the morphological approach (The relative abundance obtained from the three replicatecores pooled)

genera were: Sabatieria (12\%), Daptonema (11\%) and Ptycholaimellus (9\%). The Copepoda (Arthropoda), the second most abundant taxa, were classified into 7 genera (Robertgurneya, Cletodes, Normanella, Mesochra, Bradya, Bryocamptus and Tigriopus). The Polychaeta (Annelida), the third most abundant taxa, were identified to the family level as Lumbrineridae, Onuphidae, Serpulidae and Polygordiidae. Some soft-bodied animals (representing $2 \%$ of all meiofauna) were poorly preserved, precluding their identification, and they were noted as "unidentified". Among non-metazoans, only Foraminifera were found, and as they represented $1 \%$ of the total abundance, they were not included in the analysis of meiofauna.

\section{Molecular assessment of meiofaunal diversity}

Sequencing yielded a total of 191,983 sequences. After quality filtering, 144,011 high-quality sequences over 200 bases were obtained. In total, 4717 OTUs were obtained and assigned according to the Silva database. The majority of OTUs (4415) belonged to metazoans (16 phyla), while 302 OTUs were assigned to other eukaryotes: Alveolata, Stramanopiles, Fungi, Chlorophyta, Rhizaria, Amebozoa and Rhodophyceae. For downstream diversity analysis, we used the similarity cut-off of $96 \%$, previously shown to best reflect levels of taxonomic diversity (Fonseca et al. 2010, 2014; Lallias et al. 2015).

Among the 16 metazoan phyla, Nematoda (2390 OTUs) was the most OTU-rich phylum, followed by Arthropoda (1272 OTUs), Annelida (301 OTUs) and Platyhelminthes (178 0TUs) (Fig. 4). Six phyla identified by the molecular analysis (i.e., Nemertea, Hemichordata, Echinodermata, Brachiopoda, Tardigrada, Porifera, Sipunculida) were not found in the morphological inventory. These phyla were represented by a scarce number 


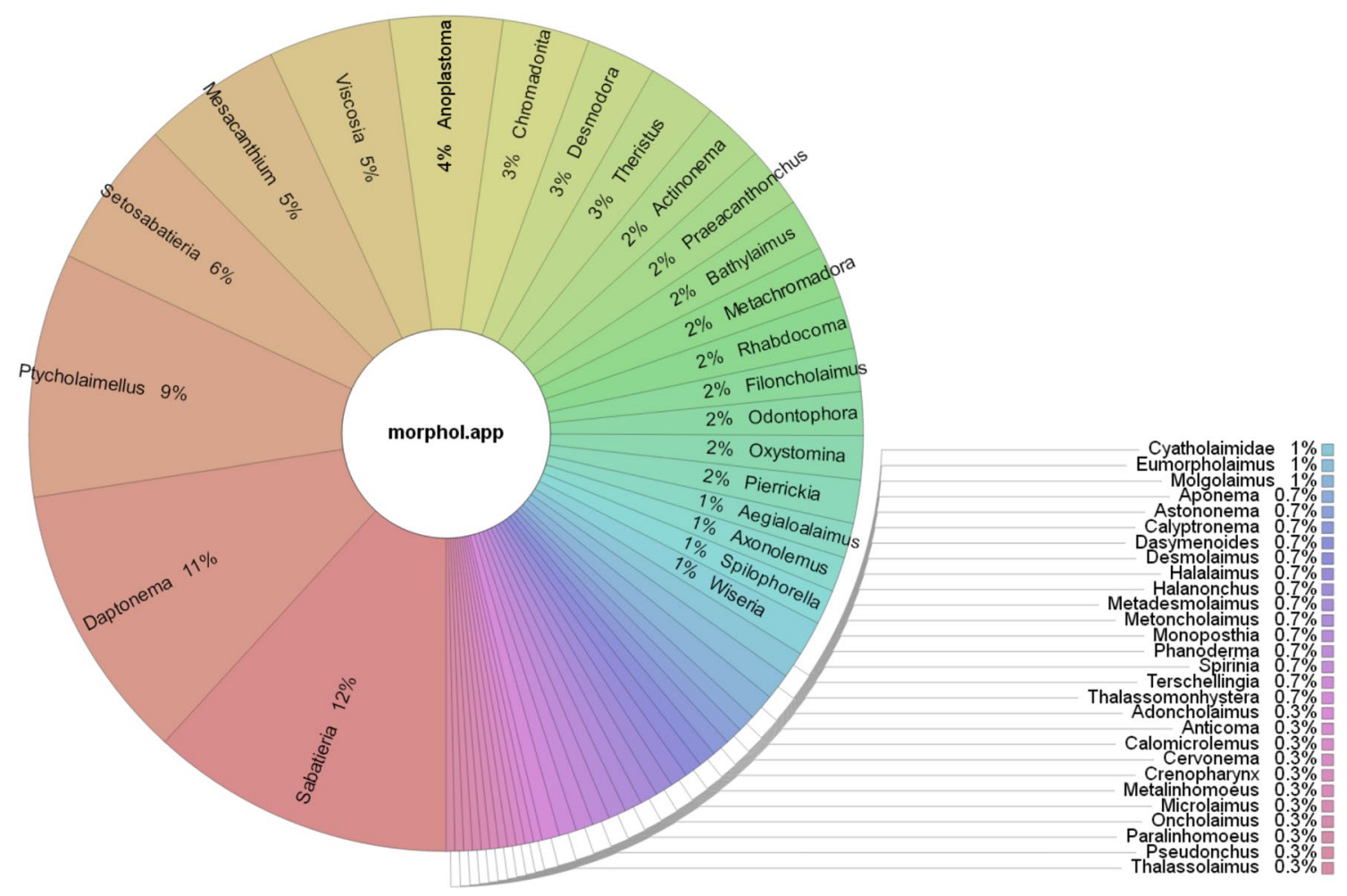

Fig. 3 Nematode diversity assessed using the morphological approach. The 300 identified nematodes were classified in 51 genera belonging to 22 families and 4 orders (The relative abundance obtained from the three replicate-cores pooled)

Fig. 4 Assessment of meiofaunal diversity using molecular approach (The relative abundance of OTUs obtained from the three replicate-cores pooled)

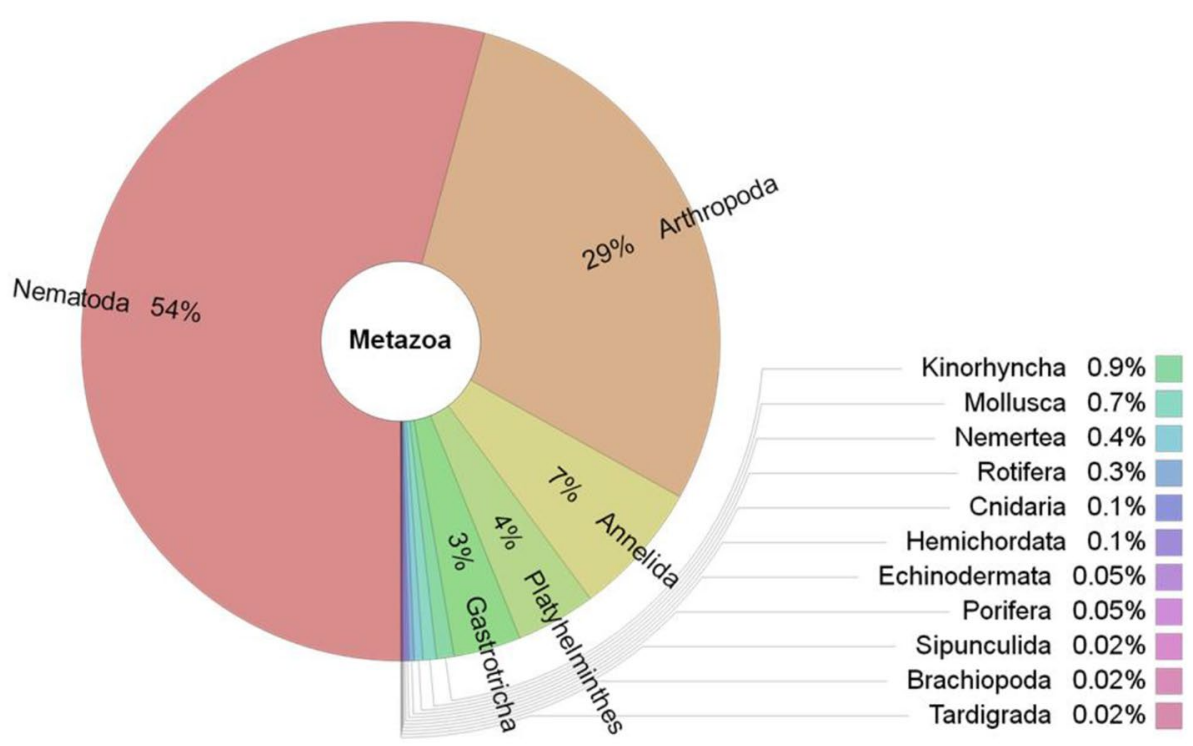

of OTUs with few sequences. The summary information obtained from the morphological and molecular datasets for the metazoans is shown in SI_3. Moreover, the comparison of the number of different OTUs across the main phyla, as well as their various levels of matching to reference sequences in the Silva database, showed that a majority of nematode OTUs uncovered in this study had no known matches in the database, similar to most of the phyla identified in the sample (Fig. 5). This suggests that these may be novel sequences. 
Fig. 5 Number of OTUs for the main phyla and their percentage identity compared with sequences in the Silva database (http://www.arb-silva de) (The relative abundance of OTUs obtained from the three replicate-cores-pooled)

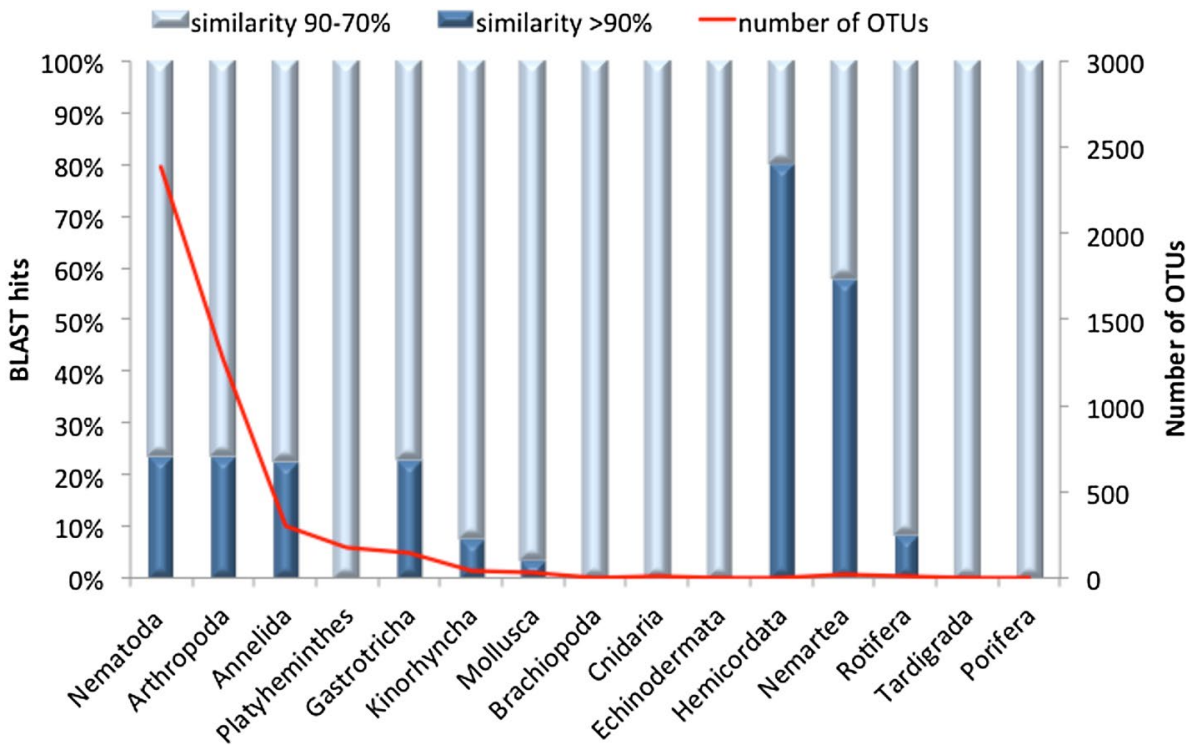

\section{Comparison of morphological and molecular approaches in assessing nematode diversity}

In total, 51 genera of nematodes were identified from the morphological approach (Fig. 3) and 42 from the molecular approach (Fig. 6). The compilation of results from molecular and morphological inventories reveals a particularly high diversity, with 73 genera belonging to 22 families and 4 orders (Fig. 7). It should be noted that 13 genera out of the 51 (i.e., 25\%) identified by the morphological approach were not present in the molecular

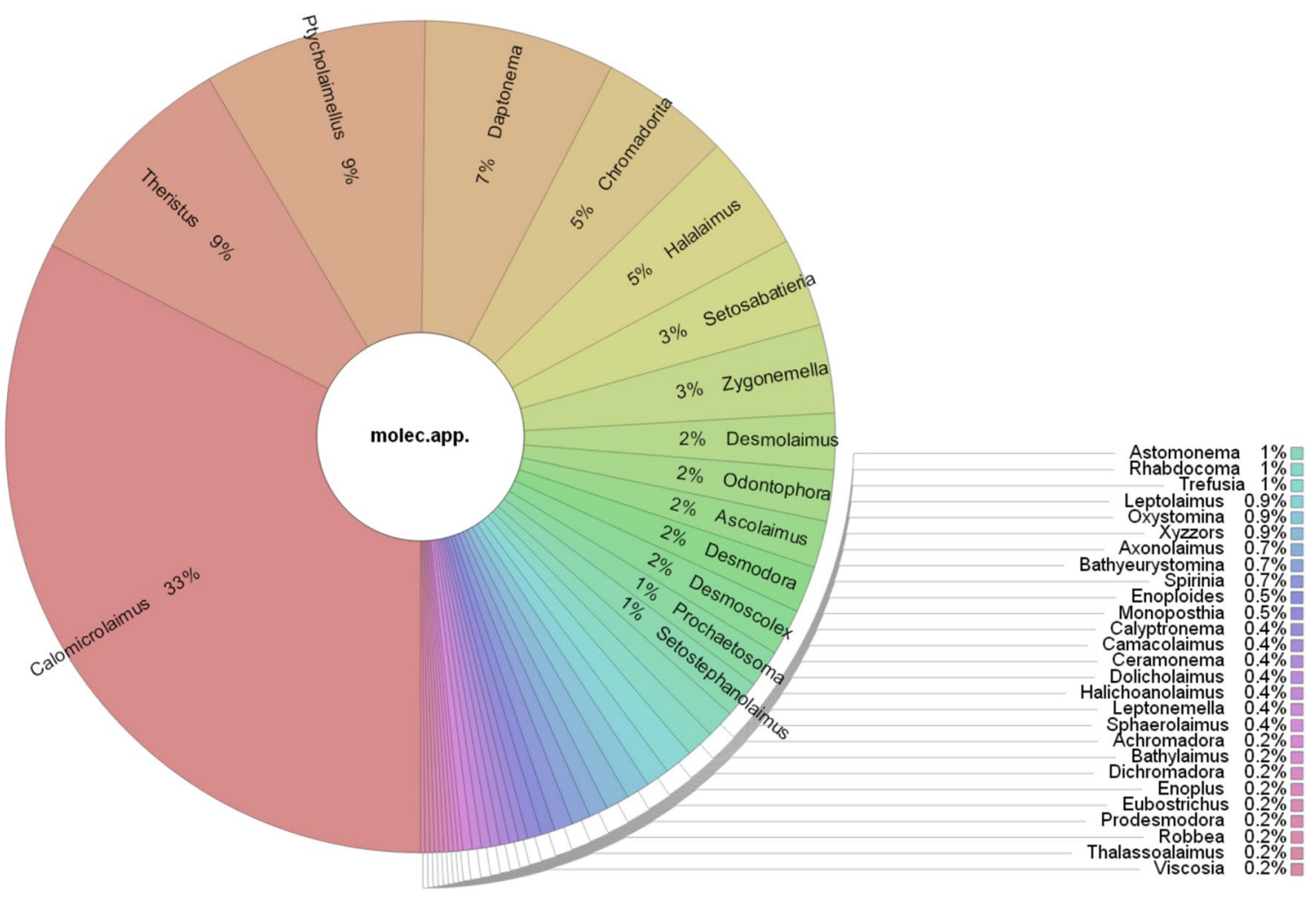

Fig. 6 Nematode diversity assessed using the molecular approach. The 552 OTUs assigned to nematode at genus level were classified in 42 genera belonging to 20 families and 4 orders (The relative abundance of OTUs obtained from the three replicate-cores pooled) 


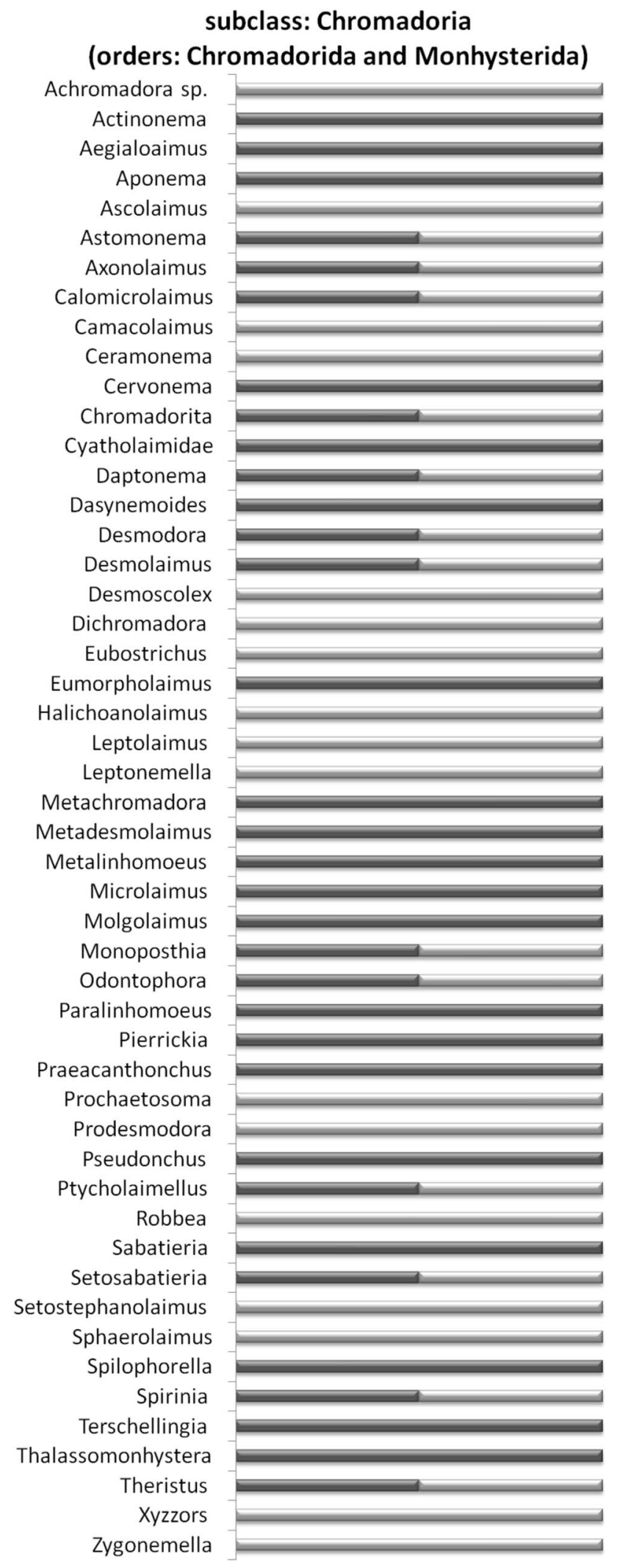

Fig. 7 Nematode genera identified by morphological and molecular approaches. The bars indicate that genus was found using morphological method (dark bar) or molecular method (gray bar)

\section{subclass: Enoplia \\ (orders: Enoplida and Trefusiida)}

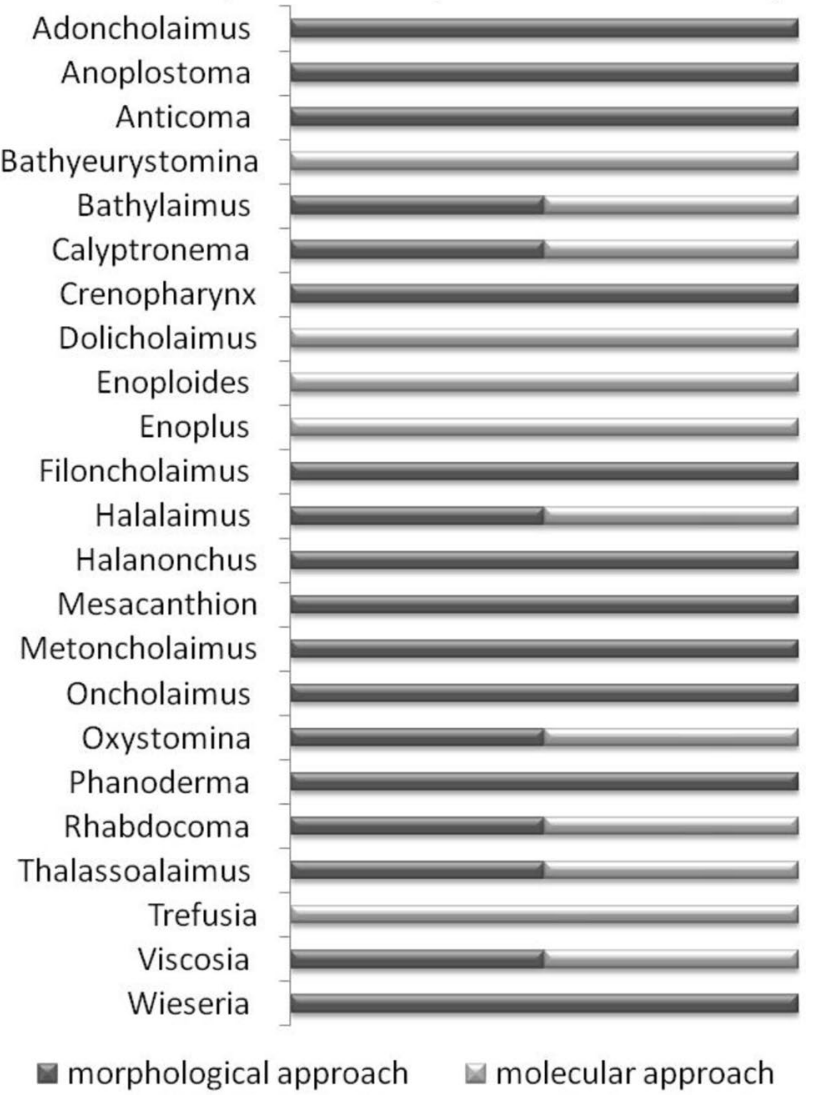

Fig. 7 (continued)

survey, suggesting that these genera have no matches present in the Silva database.

The Bray-Curtis analysis, in which an index of $100 \%$ denotes the highest similarity, revealed a similarity of $42 \%$ between morphological and molecular datasets and a similarity of $62 \%$ between the three morphological replicates. The slope of rarefaction curves did not approach an asymptote, suggesting that nematode diversity was not exhaustively characterized neither by morphological, nor by molecular method (Fig. 8).

\section{Discussion}

This study is the first to compare morphological and molecular survey of meiofaunal diversity from a coastal NorthWestern Mediterranean sedimentary site. The traditional morphological approach is a long-established and validated method upon which the quantitative and qualitative analysis of meiofaunal diversity can be firmly established (Higgins and Thiel 1988; Giere 2009), provided that attention is paid to extraction methods. The meiofaunal abundance 
Fig. 8 Rarefaction curves based on the number of sampled specimens against the number of identified nematode genera by morphological method and the number of OTUs against the number of identified OTUs at genera level by molecular method

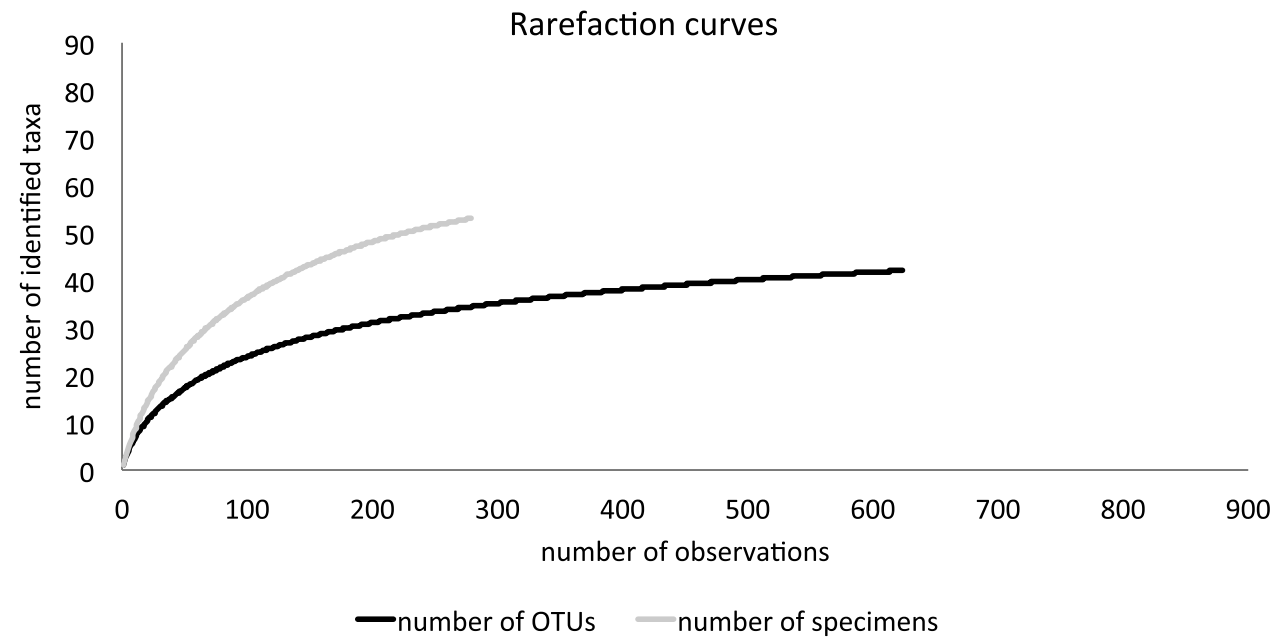

determined in this study $\left(1341 \pm 356\right.$ ind $\left..10 \mathrm{~cm}^{-2}\right)$ exceeds previous records in the Bay of Banyuls-sur-Mer (38 to 685 ind. $10 \mathrm{~cm}^{-2}$, Guille and Soyer 1974; Soyer 1971). This difference likely reflects natural variability, however, it may also be due to the use of different methods for meiofauna separation from sediment. In the present study, the meiofauna was sieved on a $40 \mu \mathrm{m}$ mesh and then extracted with a Ludox solution, a procedure allowing an extraction efficiency of $90 \%$ (Heip et al. 1985; Giere 2009). Previous studies (Guille and Soyer 1974; Soyer 1971) sieved the sediment on a $83 \mu \mathrm{m}$ mesh and relied on the decantation method, which is less efficient for quantitative analyses (Higgins and Thiel 1988). Our results compare well with those reported in Grémare et al. (2002) for the Gulf of Lion, where the abundances varied from 1266 to 5587 ind $10 \mathrm{~cm}^{-2}$, with the same extraction protocol.

The meiofaunal morphotaxonomic diversity (10 phyla) still exceeds the diversity previously described in the Gulf of Lion, varying between 5 and 7 phyla (Guille and Soyer 1968; Grémarre et al. 2002) reflecting the wide variability of these communities over space and time. The morphological assessment of meiofaunal richness indicated that Nematoda were the most dominant (77\%), far ahead Arthropoda (17\%) and Annelida (3\%), which ranked second and third, respectively. These relative abundances were overall consistent with meiofaunal richness assessed for the Gulf of Lion (Grémare et al. 2002).

While the present or previous studies placed Platyhelminthes among very rare or absent phyla in morphological inventories (Grémare et al. 2002), the molecular analysis revealed the importance of this phylum. Indeed, the molecular assignment ranked Platyhelminthes OTUs as the fourth richest phylum after Nematoda, Arthropoda and Annelida. These results are consistent with those of Fonseca et al. (2010) and Lejzerowicz et al. (2015), which revealed the unexpected importance of Platyhelminthes in the molecular inventories of meiofauna. As this phylum is considered rare in morphotaxonomic inventories, these findings suggest that a review of its relative importance is now necessary.

Several reasons can explain the lower diversity identified from morphological versus molecular assessments. First, morphological observations are made on sub-samples (e.g., split in two or four after ludox extractions) to facilitate the analysis and reduce the identification time. However, this procedure can lead to an underestimation of some rare taxa. Conversely, in the molecular approach, the entire samples were used for DNA extraction, thereby enhancing the chances to capture the rare taxa. Another plausible artefact might be the poor preservation of soft-bodied taxa with the traditional method, particularly the use of formalin, which induces degradation of soft-bodied meiofauna such as Plathelminthes and Nemertea (Higgins and Thiel 1988; Curini-Galletti et al. 2012). Unlike samples for morphological identification that were preserved in $4 \%$ formalin, unpreserved samples were used for molecular analysis, avoiding this potential preservation bias.

Nevertheless, both methods consistently show that meiofaunal phyla are dominated by the nematodes. Beyond the Nematode phylum level, further trends can be explored within the datasets. Both approaches confirmed the high diversity found in the nematode assemblage, and in total, 73 genera belonging to 22 families and 4 orders were identified, which is among the highest values in the range of morphologically based diversity reported in the Mediterranean Sea (Danovaro et al. 2000). Out of 73 genera, morphological analysis detected 51 genera. Even if molecular analysis provided only 42 genera, 22 of them were not detected by morphological method. The detected genera were provided by morphological analysis alone (42.5\%), molecular analysis alone $(30.1 \%)$ and both methods $(27.4 \%)$. It should be recalled that the morphological method identifies 51 genera out of 300 individuals. Even if OTUs and individuals 
cannot compare directly, the rarefaction curves (Fig. 8) show that with 300 OTUs 35 genera should be obtained. It is rather unexpected that, out of 2390 OTUs assigned to nematodes, molecular method contributed less than the morphological method to diversity assessment. It should be noted that only 552 OTUs (23\%) could be assigned to the genera. Thus, the missing diversity might well be hidden in the remaining $77 \%$ OTUs.

At present, the morphological method appears more effective in identification of nematode genera. Both the state of development of the reference database and the sampling variability may influence the results. First, about half of the genera undetected by the molecular approach had no known matches in the Silva database, making their identification impossible. Second, some genera had very low abundances, and thereby, they may be not present in the extracted DNA from the samples. Although both approaches used the same sediment cores split on two equal parts, meiofaunal assemblages may substantially differ on the mm- to cm-scale ( $\mathrm{Li}$ et al. 1997; Giere 2009; Ingels and Vanreusel 2013) and this spatial heterogeneity could hamper the ability to obtain two identical assemblages for analysis by the two methods. This may be partly reflected in the difference between the morphological and molecular portion of a sample.

An unexpected result was that the best-represented genus in the morphological inventory, Sabatieria, was not detected by the DNA-based approach even if present in the Silva database. Thus, no sequences from Sabatieria were obtained after PCR. It may reflect the lack of specificity of primers for this nematode. The focus on meiofauna in general, not just nematodes, lead to use universal primers that target a wide array of eukaryotic taxa. A recent study suggests the use of a more specific primer set for nematodes so that PCR is more effective to amplify the templates (Porazinska et al. 2009). Another possibility of PCR error may be the presence of inhibitors in the sample, generation of artificial DNA sequences (Coissac et al. 2012) or competitive nature of PCR (Porazinska et al. 2009). Thus, there are a few possible, non-mutually exclusive explanations for these discrepancies. However, only a specific study on primers would determine whether a multi-locus amplification would allow a better description of meiofaunal diversity compared to the unique primer method used here.

An important methodological limitation in most studies is the reliance upon DNA extracted directly from the sediment sample, which leads to the co-extraction of humic substances present in large amounts in the sediment (Pawlowski et al. 2011). The humic substances co-extracted during DNA retrieval greatly inhibit the enzymes involved in manipulating DNA, and various commercial kits available for soil DNA extraction are usually unable to overcome the problem (Dong et al.
2006). To address this issue, the DNA was extracted from organisms previously separated from the sediment and the commercial kits were substituted using a classical DNA extraction method (Winnepenninckx et al. 1993) in the present study. Rigorous sieving and washing of organisms on $40 \mu \mathrm{m}$ mesh prior to DNA extraction were applied to remove the majority of extracellular DNA and the remains of dead organisms. As such, these methods should limit the possibility that some metazoan OTUs correspond to dead organisms or extracellular DNA preserved in the sediment.

Previous metabarcoding studies on meio- or macrobenthos from intertidal zones or deep-sea also found that the number of meiofaunal phyla assessed by molecular approach was higher than those previously identified by morphological assessments (Creer et al. 2010; Fonseca et al. 2010; Pawlowski et al. 2011; Bik et al. 2012; Lallias et al. 2015; Cowart et al. 2015; Lejzerowicz et al. 2015). The discrepancy between the two datasets clearly illustrates the non-exhaustive nature of assessments obtained with the morphotaxonomic assessments. For example, Lejzerowice et al. (2015) pointed out that the most striking difference between morphological and molecular data was that numerous OTUs could be assigned to Platyhelminthes, whereas these meiofaunal taxa were not included in the morphotaxonomic inventory. The molecular methods are particularly useful for uncovering "temporary meiofauna", juveniles of macrofauna and early developmental stages (eggs, larvae) of metazoans (Lejzerowicz et al. 2015; Cowart et al. 2015). Moreover, mobile species native to the community might escape the sampling; therefore, they may be not taken into account in morphological inventories. The molecular analyses can provide information on organisms having left biological footprints as scales, mucus or other remains; therefore, the presence of these species may be recorded (Dafforn et al. 2014; Cowart et al. 2015). These previous studies highlighted that compared to the traditional morphological inventory, metaborcoding provides a more holistic view of the meiofaunal diversity.

Drawing conclusions from the comparison of meiobenthic phyla in different studies is challenging, because different protocols were used, i.e., sampling surfaces and nSSU regions for primer design. Particularly, there is an ongoing debate over which of the variable $18 \mathrm{~S}$ regions are most applicable for biodiversity studies. Recent results suggested that the V2, V4 and V9 regions were the best suited for biodiversity assessments (Hadziavidic et al. 2014). In the present study, the primers used here were chosen to anneal the V4-V5 regions of the 18S rRNA gene. According to Hadziavidic et al. (2014), the V4 region is well suited for the biodiversity assessment for eukaryotes, because it is the longest variable region in the 18S rRNA gene with the highest length of polymorphism and yields the highest 
taxonomic resolution at cut-off values ranging from 95 to $100 \%$ of the sequence identity (Hadziavidic et al. 2014).

\section{Conclusions}

The study supports the suitability of DNA sequencing technologies and molecular analysis approaches for the identification of meiofaunal taxa from marine sediments. The molecular analysis, however, is more sensitive in detecting rare phyla and reinforces the idea that morphology-based knowledge of meiofauna in marine sediments is largely incomplete. Our study further identifies steps to improve molecular-based identification, particularly for lower taxonomic levels (i.e., the genera/species of nematodes). A specific study on primer suitability would be needed to determine whether a multi-primer approach would allow a better description of meiofaunal diversity compared to the unique primer method used here. Additionally, further improvement of reference databases will allow identification of unknown sequences. Because many unsequenced taxa exist in marine sediments, DNA-sequencing of all morphologically identified species is a prerequisite that will require a close collaboration between taxonomists and molecular biologists.

\begin{abstract}
Acknowledgements This research received support from CNRS as the APEGE programme (incentive funds from the Institute of Ecology and Environment - InEE). Additional support was obtained from the chair of biodiversity, extreme marine environments and global change supported by Foundation TOTAL. We acknowledge Hervé Moreau for his support and stimulating discussions, Nigel Grimsley and Wiley Edition Services for English correction. We thank Jean-Claude Roca and Bruno Hesse, the scuba divers, and the R/V crew Nereis II of the Observatoire Océanologique in Banyuls-sur-Mer. We thank anonymous reviewers for improvement of the manuscript.
\end{abstract}

\section{Compliance with ethical standards}

Funding This study was partly funded by the chair of biodiversity supported by Foundation TOTAL (J091I006).

Conflict of interest All authors declared they have no conflict of interest.

Ethical approval All applicable international, national, and/or institutional guidelines for the care and use of animals were followed.

\section{References}

Bik HM, Way S, de Lay P et al (2012) Metagenetic community analysis of microbial eukaryotes illuminates biogeographic patterns in deep-sea and shallow water sediments. Mol Ecol 21:1048-1059

Bonaglia S, Nascimento FJA, Bartoli M, Klawonn I, Brüchert V (2014) Meiofauna increases bacterial denitrification in marine sediments. Nat Commun 5:1-9
Caporaso JG, Kuczynski J, Stombaugh J et al (2010) QIIME allows analysis of high-throughput community sequencing data. Nat Methods 7:335-336

Clarke KR, Warwick RM (2001) Change in marine communities: an approach to statistical analysis and interpretation. PRIMERE, Plymouth

Coissac E, Riaz T, Puillandre N (2012) Bioinformatic challenges for DNA metabarcoding of plants and animals. Mol Ecol 21:1834-1847

Cowart DA, Pinheiro M, Mouchel O et al (2015) Metabarcoding is powerful yet still blind: a comparative analysis of morphological and molecular surveys of seagrass communities. PLoS One 10(2):e0117562. doi:10.1371/journal.pone.0117562

Creer S, Fonseca VG, Porazinska DL et al (2010) Ultrasequencing of the meiofaunal biosphere: practice, pitfalls and promises. Mol Ecol 19:4-20

Curini-Galletti M, Artois T, Delogu V et al (2012) Patterns of diversity in soft-bodied meiofauna: dispersal ability and body size matter. PLoS One 7(3):e33801. doi:10.1371/journal. pone. 0033801

Dafforn KA, Baird DJ, Chariton AA et al (2014) Faster, higher and stronger? The pros and cons of molecular faunal data for assessing ecosystem condition. Adv Ecol Res 51:1-40

Danovaro R, Tselepides A, Otegui A, Della Crose N (2000) Dynamics of meiofaunal assemblages on the continental shelf and deep-sea sediments of the Cretan Sea (NE Mediterranean): relationships with seasonal changes in food supply. Prog Oceanogr 46:367-400

Dell'Anno A, Carugati L, Corinaldesi C, Riccioni G, Danovaro $\mathrm{R}$ (2015) Unveiling the biodiversity of deep-sea nematodes through metabarcoding: are we ready to bypass the classical taxonomy? PLoS One 10(12): e0144928. doi:10.1371/journal. pone. 0144928

DeLong EF, Preston CM, Mincer T et al (2006) Community genomics among stratified microbial assemblages in the ocean's interior. Science 311:496-503

Dong D, Yan A, Liu H, Zhang X, Xu Y (2006) Removal of humic substances from soil DNA using aluminium sulphate. J Microbiol Methods 66:217-222

Edgar RC, Haas JB, Clemente JC, Quince C, Knight R (2011) UCHIME improves sensitivity and speed of chimera detection. Bioinformatics 27:2194-2200

Fauvel P (1923) Polychaetes errantes. Fauna de France, Fédération Française des Sociétés de Sciences Naturelles

Fonseca VG, Carvalho GR, Sung W et al (2010) Second-generation environmental sequencing unmasks marine metazoan biodiversity. Nat Commun 1:1-8

Fonseca VG, Carvalho GR, Nichols B et al. (2014) Metagenetic analysis of patterns of distribution and diversity of marine meiobenthic eukaryotes. Glob Ecol and Biogeogr 23:1293-1302

Giere O (2009) Meiobenthology: the microscopic motile fauna of aquatic sediments. Springer, Berlin

Grémarre A, Madernach L, De Bovée F et al (2002) Relationships between sedimentary organics and benthic meiofauna on the continental shelf and the upper slope of the Gulf of Lions (NW Mediterranean). Mar Ecol Prog Ser 234:85-94

Guille A (1970) Bionomie benthique du plateau continental de la côte catalane française. II- Les communautés de la macrofaune. Vie \& Milieu 21:149-280

Guille A (1971) Bionomie benthique du plateau continental de la côte catalane française IV-Densités, biomasses et variations saisonnières de la macrofaune. Vie \& Milieu 22:93-158

Guille A, Soyer J (1968) La faune benthique des substrats meubles de Banyuls-sur-Mer. Premières données qualitatives et quantitatives. Vie \& Milieu 19:323-360 
Guille A, Soyer J (1974) Bionomie benthique du plateau continental de la côte catalane française. Macrofaune et méiofaune, rapports quantitatifs et biocénotiques. Vie \& Milieu 24:301-320

Hadziavdic K, Lekang K, Lanzen A et al (2014) Characterization of the 18S rRNA Gene for designing universal eukaryote specific primers. PLoS One 9(2):e87624. doi:10.1371/journal. pone. 0087624

Hammer Ø, Harper DAT, Ryan PD (2001) PAST: Paleontological statistics software package for education and data analysis. Palaeontologia Electronica 4(1): 9

Heip C, Vincx M, Vranken G (1985) The ecology of marine nematodes. Oceanogr Mar Biol 23:399-489

Higgins RP, Thiel H (1988) Introduction to the study of meiofauna. Smithsonian Institution Press, Washington

Huys R, Gee JM, Moore CG, Hamond R (1996) Marine and brackish water Harpacticoid Copepods part 1. Synopses of the British fauna (new series), no. 51. The Linnean Society of London and The Estuarine and Coastal Sciences Association, Field Studies Council Shrewsbury, UK

Ingels J, Vanreusel A (2013) The importance of different spatial scales in determining structural and functional characteristics of deep-sea infauna communities. Biogeosciences 10:4547-4563

Ingels J, Van den Driessche P, De Mesel I et al (2010) Preferred use of bacteria over phytoplankton by deep-sea nematodes in polar regions. Mar Ecol Prog Ser 406:121-133

Labrune C, Grémare A, Guizien K, Amouroux JM (2007) Long-term comparison of soft bottom macrobenthos in the Bay of Banyulssur-Mer (north-western Mediterranean Sea): a reappraisal. J Sea Res 58:125-143

Lallias D, Hiddink JG, Fonseca VG et al. (2015) Environmental metabarcoding reveals heterogeneous drivers of microbial eukaryote diversity in contrasting estuarine ecosystems. Intl Soc Microbial Ecol 9:1208-1221

Lambshead PJD, Boucher G (2003) Marine nematode deep-sea biodiversity-hyperdiverse or hype? J Biogeogr 30:475-485

Lang K (1975a) Monographie der Harpacticiden, 1. Otto Koeltz, Koenigstein

Lang K (1975b) Monographie der Harpacticiden, 2. Otto Koeltz, Koenigstein

Lejzerowicz F, Esling P, Pillet L et al. (2015) High-throughput sequencing and morphology perform equally well for benthic monitoring of marine ecosystems. Sci Rep 5:1-10. doi:10.1038/ srep13932

Li J, Vincx M, Herman PMJ, Heip C (1997) Monitoring meiobenthos using cm-, m- and km-scales in the Southern Bright of the North Sea. Mar Environl Res 43:265-278

Nascimento FJA, Näslund J, Elmgren R (2012) Meiofauna enhances organic matter mineralization in soft sediment ecosystems. Limnol Oceanogr 57:338-346

Ondov BD, Bergman NH, Phillippy AM (2011) Interactive metagenomic visualization in a Web browser. BMC Bioinf 12:1-9

Pawlowski J, Christen R, Lecroq B et al (2011) Eukaryotic richness in the abyss: insights from pyrotag sequencing. PLoS One 6(4):e18169. doi:10.1371/journal.pone.0018169
Platt HM, Warwick RM (1983) Free living marine nematodes. Part I. British Enoplids. Synopses of the British fauna (new series), no. 28. The Linnean Society of London and The Estuarine and Coastal Sciences Association, Cambridge University Press, Cambridge

Platt HM, Warwick RM (1988) Free living marine nematodes. Part II. British Chromadorids. Synopses of the British fauna (new series), no. 38. The Linnean Society of London and The Estuarine and Coastal Sciences Association, E.J. Brill/Dr W. Backhuys, Leiden, New York, Kobenhavn, Köln

Platt HM, Warwick RM, Somerfiels PJ (1988) Free living marine nematodes. Part III. Monhysterids. Synopses of the British fauna (new series), no. 53. The Linnean Society of London and The Estuarine and Coastal Sciences Association, Field Studies Council Shrewsbury, UK

Porazinska DL, Giblin-Davis RM, Faller L et al (2009) Evaluating high-throughput sequencing as a method for metagenomic analysis of nematode diversity. Mol Ecol Resour 9:1439-1450

Quince C, Lanzen A, Davenport RJ, Turnbaugh PJ (2011) Removing noise from pyrosequenced amplicons. BMC Bioinform 12:1-18

Rothberg JM, Leamon JH (2008) The development and impact of 454 sequencing. Nat Biotechnol 26:1117-1124

Schloss PD, Westcott SL, Ryabin T et al (2009) Introducing mothur: open-source, platform-independent, community-supported software for describing and comparing microbial communities. Appl Environ Mocrobiol 75:7537-7541

Snelgrove PVR (1999) Getting to the bottom of marine biodiversity: sedimentary habitats - ocean bottoms are the most widespread habitat on Earth and support high biodiversity and key ecosystem services. Bioscience 49:129-138

Sogin ML, Morrison HG, Huber JA et al (2006) Microbial diversity in the deep sea and the underexplored 'rare biosphere'. Proc Natl Acad Sci USA 103:12115-12120

Soyer J (1970) Bionomie benthique du plateau continental de la côte catalane française. III. Les peuplements de Copepodes harpacticoides (Crustacea). Vie milieu 21:337-511

Soyer J (1971) Bionomie benthique du plateau continental de la cote catalane Frangaise. V. Densites et biomasses du meiobenthos. Vie Milieu 22:351-424

Soyer J (1974) Contribution à l'étude des Copépodes Harpacticoïdes de Méditerranée occidentale. Vie Milieu 24:379-408

Tang CQ, Leasi F, Obertegger U et al (2012) The widely used small subunit $18 \mathrm{~S}$ rDNA molecule greatly underestimates true diversity in biodiversity surveys of the meiofauna. Proc Natl Acad Sci USA 40:16208-16212

Westheide W (1990) Polychaetes : Interstitial families. Synopses of the British fauna (new series), no. 44. The Linnean Society of London and The Estuarine and Coastal Sciences Association, Universl Book Services/Dr W. Backhuys, Oegstgeest

Winnepenninckx B, Backeljau T, De Wachter R (1993) Extraction of high-molecular-weight DNA from molluscs. Trends Genet 9:407 